\title{
TURNING VISITORS INTO USERS STRATEGIES FOR THE MUSEUM IN THE 21ST CENTURY
}

\author{
James M. Bradburne
}

Our museums are in crisis - assailed on two sides by changes that threaten the very core of the institution's mission. On the one hand, museums, the repositories of the real, are becoming victims of their own success. The enormous number of visitors drawn to large museums by 'blockbuster' exhibitions and aggressive marketing now makes it almost impossible for those visitors to experience the museum collection in any but the most trivial sense. On the other hand, many smaller museums are seeing visitor numbers drop drastically, as the museum visit is considered to be 'old-fashioned', and many new educational opportunities formerly provided by the museum visit are now available, at home, on the computer. It is the position of this paper that to survive into the next century, our museums must augment those experiences which can only be had in situ, while aggressively exploiting new approaches to informal learning.

\section{THE INFORMAL LEARNING ENVIRONMENT}

Before I continue, let me first define what I mean by informal, as opposed to formal, learning. The key feature that distinguishes the museum from the school, or more broadly, the informal setting from the formal one can be summarised succinctly in the words of Frank Oppenheimer, founder of the San Francisco Exploratorium, one of the first, and still one of the world's most innovative science centres. He said 'nobody ever failed a museum'. In a scho- ol, the student must be carefully modelled, in terms of prerequisite knowledge and abilities, and carefully evaluated, in order to ensure the coherent and standardised acquisition of knowledge. In a museum, the visitor is defined by the act of visiting - there are no pre-visit qualifications and no post-visit tests. Our visitors are unknown, and, perhaps more importantly, unknowable. In the formal system, the student is responsible for learning. In the informal system, the institution is responsible for creating learning opportunities. A student can fail a school- 
40 but only the museum can fail its visitors.

The two systems, although complementary, are like oil and water - they do not mix. The formality we speak of in the learning environment is not just a question of style - dusty classrooms and boring lectures versus interactive experiences and jolly good fun. An interactive programme set in the science centre, on whose success or failure a student passes or fails, remains a formal experience - even if it is not conducted in the classroom. On the other hand, an evening lecture series in a classroom, voluntarily entered into and unrelated to passing or failing, is informal, wherever it happens to take place. Even though they often work in consort, and are both concerned with education, the formal and informal systems are distinct, independent, and parallel. The formal system thinks in terms of students, the informal system, in terms of learners.

The museum, by definition, is an informal learning environment. Its unique character is that it is the home of the real real objects, real phenomena, real people. One of its foremost goals is to provide users with sufficient interpretive tools to decode the world they live in - to make sense of the real. George Goode Brown, director of the Smithsonian Institution in the last century wrote,

An efficient educational museum may be described as a collection of labels, each illustrated by a wellselected specimen.

Or, put another way almost a century later, Nelson Goodman wrote that

the museum has to function as an institution for the prevention of blindness in order to make works work. And making works work is the museum's major mission. Works work when, by stimulating inquisitive looking, sharpening perception, raising visual intelligence, widening perspectives, and marking off neglected significant kinds, they participate in the organisation and reorganisation of experien$\mathrm{ce}$, in the making and re-making of our worlds.

\section{A BRIEF HISTORY OF THE MUSEUM}

In order to look into the future with any hope of success, one must first look into the past. Very crudely speaking, we can consider the history of the museum as having been shaped by two models, often in tension - the library, and the collection. The library is a resource, and it puts the accent on use, especially directed by the user himself. The organisation of a library is a function of its use. The collection, on the other hand, is meant to be displayed, and its identity is bound to the collector, or more recently, the curator. The organisation of a collection is a function of the messages its organiser wishes to communicate. The prime consideration of the library is the user - of the collection, the visitor.

The earliest museum of which we can speak was in fact a library - the 'mousseion' of Alexandria, the institutional sibling of the famous library that flourished three centuries before Christ. However, since the Renaissance, the dominant model of the museum has been the collection, and the demands of the collection have taken precedence. For example, let us take Rudolph IIs Kunstkammer as a collection par excellence. Publicly, it was an instrument of power, and played an important role in legitimating the Habs- 


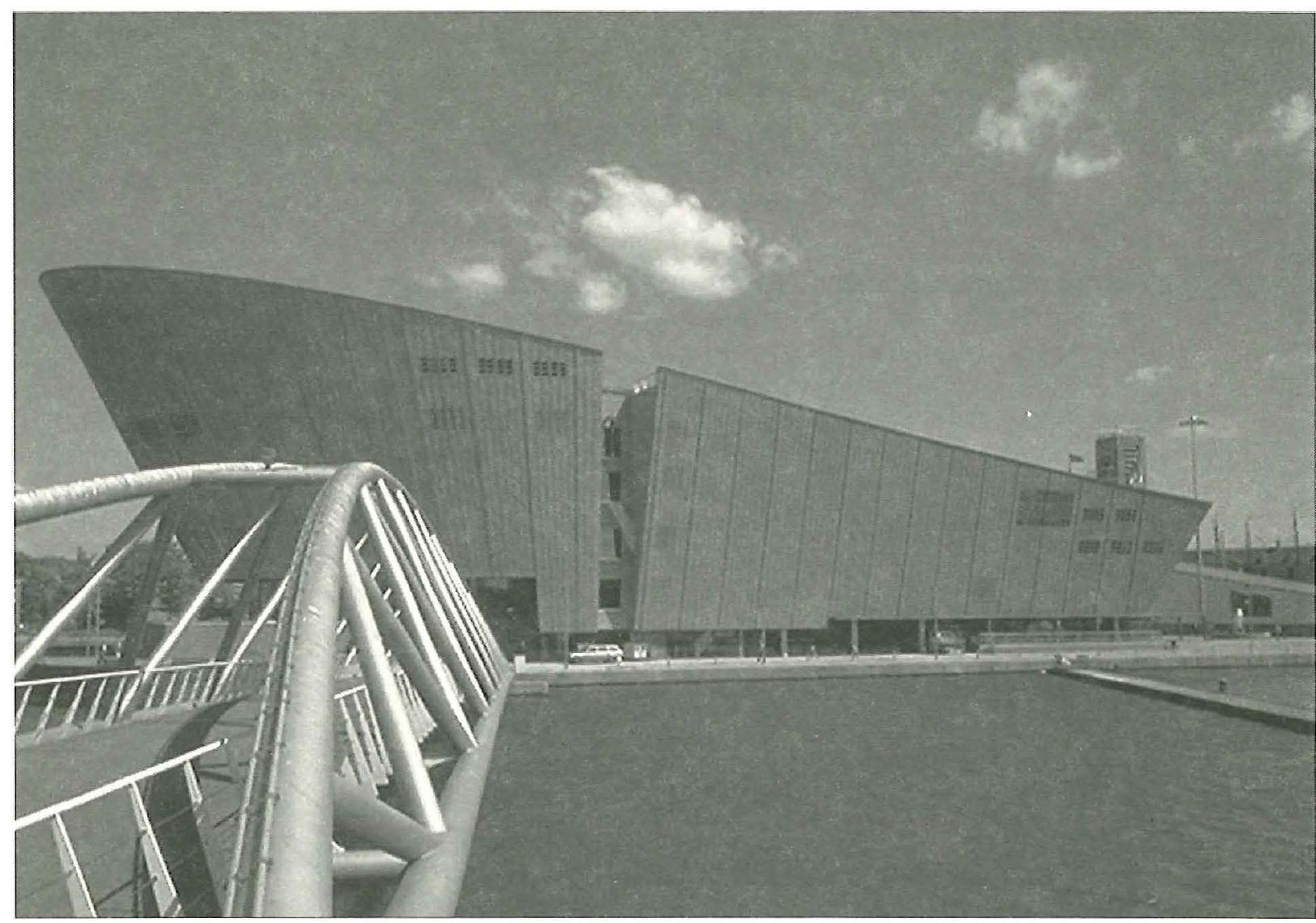

newMetropolis, Amsterdam - towards the museum of the future? Photo by newMetropolis.

burg's dynastic claims. The reputation of Rudolph's Kunstkammer - the most extensive in Europe - was widespread, and a private view, in the company of the Emperor, or more commonly with one of his artist chamberlains, was a titbit to dangle in front of august emissaries - or withhold as a sign of imperial disfavour. Privately, the Kunstkammer's role was equally important, as an indispensable adjunct to Rudolph's occult and alchemical investigations. As has been noted by art historians for some time, the Kunstkammer functioned generally as a 'theatrum mundi', and in certain specific cases, as a memory theatre. By bringing together objects, images, and texts representing in miniature the enormity of the world at large, these correspondences enabled the emperor to establish dominion over his world.

The collection, by definition, is local, specific, and until recently, largely immobile. Even today, most object-based museums remain rooted to their location - regardless of the provenance of the objects themselves, which have often travelled great distances to get there as the fruits of patronage or the spoils of war.

Nevertheless, as long as ideas are mobile, technology resists containment. Even in the Renaissance, there was enormous fluidity within the world of collectors. Painting that could not be had in the ori- 
ginal were copied (Rudolph had his painters copy hundreds of works). Coins, cast in series for centuries, were a common and readily transported form of collection. Books circulated in manuscript, and, after the invention of the printing press, in printed form. This meant that engravings could be diffused throughout Europe readily and relatively inexpensively. Foreshadowing Malraux's Musée imaginaire by several centuries, entire museums were written accounts of collections that could have, or should have, existed, but never did.

This mobility highlights a tension that persists to this day, between the specificity of an experience, and its ability to be shared at a distance - in short, between its locality and its globality. It is to this tension that I will return shortly. However, despite the mobility of cultural production among the few, access was severely limited to the many, and in the 18 th century, social ferment provoked a transformation of the museum from private collection to public exhibition.

The first seeds for this transformation were sown in the turbulent decades prior to the French Revolution, when the call for a broad and democratic participation in the cultural capital was a radical demand on the part of representatives of the disenfranchised. France's first modern museums, the Muséum de l'histoire naturelle and Conservatoire des Arts et Métiers were direct products of the Revolutionary government of 1793. Yet, as in the case of the earlier American Revolution, the benefits of the dispersion of the cultural and economic capital devolved largely onto the middle classes, and the lower strata of society, while able to participate in principle, were effectively denied access to the machinery of capital and culture alike. Large segments of society had to wait another century for even the limited benefits of public education, reduced working hours and wages sufficient to permit access to the great palaces of culture. In the early part of the 20th century, museum studies in US in the first decades of the century became concerned with the visitor, his experience and his understanding. In the $30 \mathrm{~s}$ and then again in the $60 \mathrm{~s}$, social turbulence and intense debate, not so different than the debates of the Convention in 1793, brought with them demands for a broader diffusion of cultural, social and economic benefits. Museums, and the objects they contained were seen to be far from open to huge numbers of the general population; the working classes, rural inhabitants, women.

During the past quarter century, two major impulses have shaped museums.

First, as support from the state was threatened by economic recession, museums sought to increase revenues, and as a consequence the intimacy that was once the preserve of the museum was sacrificed at the altar of increased attendance. The past decades have witnessed a massive explosion of museum expansion and museum building. The building programme was driven on the one hand by the need for additional space to show existing collections, but equally by the need to show temporary exhibitions. The modern exhibition is a creature born out of a desire to increase the number of visitors. With the advent of inexpensive travel, these visitors can be drawn from a global pool of cultural tourists, and benefit the museum in terms of catalogue and 
gift sales, and fuel the region's tourist economy.

Second, since the $60 \mathrm{~s}$, museums have felt a genuine need to make their collections accessible to a greater number of people. Labelled as the dusty preserve of a privileged few, museums felt that their own collections were no longer sufficient. In order to attract new visitors, temporary exhibitions of works from other museums, or from long hidden reserves were mounted. Exhibitions had their roots in the collections of the museum. Beginning with the post-war exhibitions on modernist art in America, temporary exhibitions were seen as a way to appealing to non-traditional audiences. New museums were conceived in these new terms, and cultural landmarks like the Centre Pompidou were conceived explicitly to both increase and broaden the audience base of the traditional museum using the vehicle of temporary exhibitions.

Propelled by these twin imperatives, to increase the number and broaden the range of visitors the museum has changed its character, from dusty closet to brightly lit shopping mall.

\section{THE MUSEUM IN CRISIS - HIGHER VOLUME AND LOWER VALUE}

Have museums succeeded in meeting their two objectives?

Certainly the numbers of museum visitors have increased enormously. New museums and new exhibitions are good business, and gift shop sales are now an important source of museum revenue. Numbers have increased, to be sure, and every jumbo jet brings pilgrims to the Meccas of high culture. But increased attendance has come at a high price.

Exhibitions generate more visitors, and more visitors need larger buildings. Larger buildings, however, incur higher costs, and what was once a financial solution becomes a financial problem, and exhibitions become an ongoing financial necessity. Many museums are now faced with the difficult choice of cutting programmes to pay for the costs of building maintenance, and with the spectacular activity of the art market in recent decades they are increasingly burdened with the costs of shipping, installing and insuring the large travelling exhibitions that ensure that the flow of visitors does not diminish.

More perniciously still, the increased visitor numbers impair the museum's ability to deliver the high quality encounter with the real that is at the heart of the museum experience. Large numbers of visitors shorten and degrade every individual's ability to engage with the exhibits, and, when international tourists make up the bulk of the visitors, the local community is squeezed out almost entirely. This can only exacerbate the museum's distance from its local circumstance and its local community. And, due to the high operating costs of a large institution, the sensible strategy of actively reducing visitor numbers - by advance booking, restricting access, or allowing long queues - is clearly unacceptable.

What about the second objective, that of reaching new audiences, people who would not normally come to museums. In this regard the success is not as obvious. Most statistics, in Europe and in America, where the political agenda is explicit, show no significant broadening of the kind of people who come to our 
44 museums, just more of the same kind of people, from farther away. The museum visit is now the sine qua non of the cultural tourist, and exhibitions are cultural events of the first water. Contemporary museum-going is considered part of the «embourgeoisment» of the museum visitor, and one of the essential roles of the visit is to distinguish a "cultured" group from others. Historically museum visits were a mark of distinction, of definition, of exclusion, and this perception has changed little over the past decades, despite the concerted attempts on the part of the museum establishment.

But do our museums need all these visitors? More importantly, is the visitor getting anything out of the visit other than an affirmation of their membership in the class of museum-goers? Is the confrontation with the Mona Lisa for thirty seconds in the company of two tour bus loads tourists a real encounter? Are our museums really the preserve of the encounter with the real anymore? I would argue that they are not, nor can they be if the present trend continues. In his classic text $\mathrm{Le}$ musée imaginaire, Malraux describes at length the way in which engravings 'stood in' for the originals in the life of the 19th century art historian, artist, and poet. They did not need to see the original, but instead, worked with simulacra and representations. Is this not the promise held out by the Internet and its resources?

\section{FROM COLLECTION TO LIBRARY}

The idea of the collection is central to the identity of the museum, after all, its mission according to Joseph Veach Noble is to 'collect, to conserve, to study, to inter- pret and to exhibit' The collection is at the heart of the museum enterprise. But following the model of the collection comes at a high price - that of dependence on visitors. A collection is visited, and once visited, the visitor's task is fulfilled. The objects in a collection are exhibited displayed to a public who is often unable to engage with it due to lack of interest, inclination, or information. With their objects enshrined in vitrines, collections are often exhausted by the visit ${ }^{1}$. Notwithstanding the importance of the 'affective' or emotional impact of the museum visit ${ }^{2}$, several museum visitor studies suggest that most museum visitors come three times in a lifetime - as a child (often in a school class), as a young parent, and as a grandparent ${ }^{3}$. This pattern is of course mitigated to some extent by what the tourist industry calls VFF Visiting Family and Friends - so when your sister-in-law drops in with the kids, or your school chums passes through town for the weekend, a trip to the museum might be the perfect way to spend a Sunday afternoon. However, notwithstanding VFF, this three-visit pattern forces the museum to create temporary exhibitions as a means of generating repeat visits. In fact, the modern temporary exhibition is a creature born out of a desire to increase the number of visitors. In the 70 s, the great 'blockbuster' exhibitions such as King Tut, proved that the exhibition could also be a major money-earner, as well as a sure generator of extra visitors. Without change to generate repeat visits, or an influx of new visitors, the number of visits inevitably declines. Attempting to rely increasingly on transient tourist visits only compounds the problem by margina- 
lising the local audience. Large numbers of visitors shorten and degrade every individual's ability to engage with the exhibits, and, when international tourists make up the bulk of the visitors, the local community is squeezed out almost entire$1 y^{4}$.

This is the crisis many museums are now facing. Recent data paints a picture of growing museum attendance ${ }^{5}$. This is certainly true, if one includes the new museums and their visitors. But a closer look at the figures tells a different story ${ }^{6}$. If the attendance to new museums is discounted, many museums are seeing their visitor numbers fall annually - often dramatically in the case of 'middle-aged' institutions ${ }^{7}$. If these figures are then adjusted to eliminate the transient effect of temporary exhibitions, the picture is even bleaker ${ }^{8}$. By defining its success in terms of visits, not use, the museum slowly exhausts its pool of potential visitors. But the model of the collection is not the only one available to the museum. As we have seen, the model of the library can also claim to be part of the museum's history. In many respects, the library model offers far more opportunities. A library is both rooted to its community of users and global, in terms of the resources it makes available. As a resource centre, it can service its users in a wide variety of ways. A library is not exhausted by a visit, on the contrary, it is refreshed by it. A library is used, and as long as the library provides resources and experiences - real or virtual - that are needed by its users, then its health is guaranteed. The model of the collection cannot be remedied by money. It can only be remedied by change.

\section{FROM VISITORS TO USERS}

In the late $60 \mathrm{~s}$, the museum sector was heavily criticised for being old-fashioned, ineffective, and irrelevant. In particular, science museums were singled out for their inability to keep up with changes in science and technology, and to excite the younger generation about the material in their collections. Starting with the San Francisco Exploratorium, a new generation of informal learning institutions the so-called 'hands-on' science centres came into existence. There are now nearly 1,000 such centres worldwide, most of which based in some measure on the original Exploratorium. As these new centres did not generally have collections of objects, they were obliged to concentrate on the attractiveness and the educational value of their exhibits. This new emphasis on the interpretive environment paid large dividends in terms of the way the entire informal learning sector looked at its mission. In looking at the ways in which visitors interacted with object-less exhibits in the science centre, we learned an enormous amount about how our object-rich museums could be improved.

From the outset, ambitious claims had been made on behalf of interactive exhibits, largely at the expensive of the vitrines and the protected objects in the traditional museum. However, in a study conducted at Canada's largest science centre in 1988, Drew Ann Wake and her colleagues recorded the following startling findings: visitors tended to use hands-on exhibits for an average of under two minutes, and rarely completed them. On the other hand, the same visitors were often prepared to spend over ten times as 
46 long with simple wooden puzzles. Moreover, while working on puzzles, visitors tended to talk with each other, share experiences and strategies, and use the opportunity for exchanging information.

Establishing whether learning has occurred is a difficult business, particularly in the informal setting, where 'no-one ever fails'. Many hands-on science professionals responded to these criticisms by saying that the cognitive learning aspect was not important, it was the affective experience that mattered - the memory of the science centre would trigger future Einsteins to take up careers in science. Nevertheless, as informal educators, we were reluctant to throw away all our claims to being an educational environment, so it seemed to us that if a visitor spent no longer than 40 seconds with an exhibit, it was unlikely whether any serious learning had occurred, while still admitting the possibility of the occasional epiphany. On the other hand, while we could not say with conviction that learning had occurred if the visitor spent twenty minutes, it certainly seemed more probable. We therefore started to look at exhibits in a different light, and posed different kinds of questions.

It seemed to us that one of the most telling criticisms of many earlier science centre exhibits was the little time visitors engaged with them, the relatively low percentage of completion, and the low percentage of exhibits actually engaged with during a typical visit. Clearly something was not working. Part of the solution seemed to lie in redefining what sort of activity should be happening in the first place. Thus instead of looking for 'learning' in terms of observable cognitive gains - a series of facts learned - we had to look for sustained engagement with the activity. Instead of looking at our job as creating 'exhibits' to show visitors scientific principles, we had to look at them as 'supports' that helped structure and sustain interaction between users.

This shift entailed two important moves away from the way designers and educators had traditionally looked at their role. First, it meant that our task was to support action (or better, interaction), rather than broadcast facts - we had to become an informal learning environment, not an exhibition. Second, we had to see our visitors as users, which is to say that our success could no longer be measured in terms of numbers of visits, but in terms of repeated, thus sustained, action.

At roughly the same time, we discovered the research of the American psychologist of creativity Mihaly Czikszentmihalyi, a professor of psychology at the University of Chicago. In his first book, Beyond Boredom and Anxiety, he made a systematic study of people who engage in creative and intellectually challenging activities. In this work, Czikszentmihalyi dismantled the traditional distinction between work and play. He attacked the assumption that people engage in challenging activities, "work", only to solve basic requirements, such as income, for food and shelter.

Instead, he focused on vocations and activities that involve a high level of challenge, but are enjoyed for their own sake: chess, dance, music, art and sport. Czikszentmihalyi's theory was that

...people enjoy work, danger, and stress. The acts are 'work' in the sense that they require concentra- 
tion and discipline, yet they give enjoyment and meaning to life.

To test this hypothesis, Czikszentmihalyi interviewed a number of people who engaged in these challenging spare time activities. He discovered that these activities offered intrinsic rewards to the participant in the form of "self-confidence, contentment and a feeling of solidarity with others".

$\mathrm{He}$ also sought to find out if there were any factors which would erode this sense of well being. The participants told him that when the activity was too difficult beyond their abilities - they became anxious and unhappy. However, when the activity was too easy, participants became bored, and lost interest altogether. Here the chess analogy is useful. Playing chess against a stronger opponent produces anxiety, while playing against a poorer opponent can be dull. This research led Czikszentmihalyi to conclude that between the states of anxiety and boredom is a state, which he called 'flow', where the level of challenge matches the abilities of the participant. It is this flow experience which draws people to an activity and maximises their enjoyment of it.

Activities that manifest 'flow' are self-initiated, self-sustaining, and often self-structuring. Czikszentmihalyi defines flow as

a subjective state that people report when they are completely involved in something to the point of losing track of time and of being unaware of fatigue and of everything else but the activity itself.' [italics in original] The experience should ensure that the opportunities for action are more or less matched by the visitor's ability to act at any given time. In order for this experience to be self-sustaining, it must also create the possibility for increasing complexity, to differentiate new challenges in the environment, to integrate new abilities into our repertoire of skills.

In order to continue the 'flow' experience, the visitor should want to return, to try the exhibit again, to do it better a second, third, or fourth time.

To survive in the next century, our museums must move away from the model of the collection, its content determined from above, towards the model of the library, its function defined through use. It must not be satisfied with merely exhibiting, but must instead reason in terms of creating maximum coherence while encouraging maximum variety. It must create an informal learning environment in which the skills necessary to engage with our culture can be explored by means of all the technologies available. Our museums of the future must reason in terms of users, not visitors, and the user must be at the heart of the museum project. The challenge of the museum as it moves into the next century, is clearly to provide a high quality experience to real local users - while at the same time providing high quality encounters to increasing number of virtual users outside the walls of the institution.

\section{CONCLUSIONS}

Our museums must change if they are to meet the challenges of the next century, and the key to that change is the embracing of a museology that thinks in terms of users, instead of visitors - in its programmes, its displays, its exhibitions, and its publications. I want to leave you with some possible strategies that will help gui- 
de our institutions in the next century.

If they are to survive, our museums will be characterised by the following features:

- skills not information. The museum must stress the acquisition of new skills, not just information. These skills are largely shared by art, science, and technology alike - creativity, collaboration, abstraction, thinking in terms of systems. The common ground provided by putting the accent on skills has the effect of making less important the distinctions formerly made according to content - science, ethnology, history, fine arts. Of course information is still indispensable, but it must be linked to the skills of finding, using, and appropriating that information. This strategy recalls the humanist education of the Renaissance, and prepare the learner for all fields of endeavour. As Jonathan Miller once said, they 'prepare us for a world in which the life of the mind is a pleasure.'

- turn visitors into users - the value of the museum is created through use. Our institutions of informal learning must not be satisfied with the casual visit, nor driven by the single-minded goal to increase the numbers of visitors through the turnstiles. The museum must draw lessons from the library, not only the theme park, and provide experiences that satisfy the full range of interests and expectations. A library is not judged by the number of tourists that visit, nor by the blockbuster appeal of its presentations. The museum must create its base in the community, work with its local community to expand that base, and encourage repeat visits - real or virtual.
- high value, not high volume - our institutions must focus on creating a high value informal learning environment in all respects, and for all its users. This means exploiting the specific strengths of all the media - real things for their immediacy and specificity, public space for its conviviality, computers for their ability to engage the player, Internet for its access to global resources of both information and interaction. Exhibitions like Mine Games have shown that computer games are an effective way to create what Cziksentmihalyi calls the 'flow' experience?. Institutions like the Laboratorio dell'Immaginario Scientifico have shown the tremendous potential for creating linked group learning activities via the Internet. Institutions like ArsLab have shown the effectiveness of temporary manifestations. It is not the medium that matters most what matters is that the quality and duration of the user's engagement is maximi$\operatorname{sed}^{10}$, and that the activity can be returned to again and again.

- research and knowledge transfer - a fundamental part of a new institution's mission is to generate new knowledge about informal learning, and turn it into effective new tools for teacher training. This is a role that only a new kind of institution can play. By definition, informal learning is learning sought for its own sake - it must be self-initiated, self-directed, and above all, self-sustaining. Traditional, school-based educational research is unable to investigate these questions, as they have little or no access to a public environment in which learning is unforced. Publishers, on the other hand, are not geared to take risks in creating new educatio- 
nal tools, and lack the means of adequately testing their products prior to release. Only a public informal learning environment, with a stream of uncoerced users, can provide the research setting necessary to create the tools and the training so desperately needed by the schools, and by society ${ }^{11}$.

- think global, act local - a new learning platform must place its emphasis on what is unique to its specific locality - on what cannot be found or done somewhere else. It must put a premium on local culture, local practices, local experience. It must be firmly rooted in its local conditions, and use them to build a community commitment to the institution. In past decades, exhibits could not effectively be shared, so they had to be duplicated. However, the new media and the Internet now allow our institutions to put the emphasis on local circumstance and local culture for the physical site ${ }^{12}$ - and global culture and global circumstance for the virtual site. Global information networks allow for the first time real, virtual institutions, open to visits from around the world, and to realtime participation. This participation need not be limited to the Web site itself. Exhibits can be designed that can be actively enjoyed by international virtual participants, as well as local users, and the participation of the virtual community can actively change the state of the local activity, much as an earthquake in Tokyo can shake the market in New York. By exploiting the new media the physical scale of the institution can be tailored to local circumstances. The institution does not have to be a major capital project - unless circumstances demand it. It can be a rented storefront, a community hall, a borrowed 49 lab - any space can be appropriated to become the kind of institution needed by the community.

What can the informal system offer that the formal system cannot? Why must the museum be revitalised and renewed? Why must the museum move towards a model wherein use is more important than mere attendance? After all, if the real challenge is learning, perhaps European governments should pour more money into the formal education system, not the informal one. What makes the informal sector worth the investment? The answer is clear and compelling. The informal environment is a prime site for learning about learning, and learning to learn, and I would argue that in addition to their traditional roles of collecting, conserving, and display, museums offer two additional features - research, and reach.

First of all, research - our informal learning institutions are potentially powerhouses of learning about learning. Only the informal environment can provide governments with proof of the effectiveness of new strategies to stimulate learning. On the one hand, if thousands of students go to classes every day, this does not demonstrate either the attractiveness nor the effectiveness of the learning environment provided by the schools. Students go to school because they have to go to school. On the other hand, thousands of users daily 'vote with their feet' and pay to engage in unforced learning - and as long as we can ensure that learning occurs in the centre, then learning it is, even if it is perceived by the visitor to be fun. When our learning environments attract users it 
50 is evidence for their ability to stimulate and structure self-initiated, self-directed, and self-sustained learning. When they don't, our failure is public and painful. Success in attracting users is not enough, however. Michael Shortland's famous question of 1988 still obtains - 'but are they learning? ${ }^{13}$ Although there is still substantial debate, there is now evidence that certain interpretive strategies can promote learning ${ }^{14}$. If users come to our programmes (proving their attractiveness), and they can be shown to learn (proving their effectiveness), then we can argue that we can have knowledge about motivation and effectiveness that can be transferred into the formal setting. If the knowledge we create in the informal setting can be transferred to the formal environment, then we have not only proven the worth of the informal environment, but enriched the formal environment as well.

Second, reach - the informal system potentially provides a means to catch the increasing number of people outside of the formal system - dropouts, the unemployed, the elderly, and ethnic minorities. Because the informal system is by definition not restrictive, a broader spectrum of the public can find an opportunity to learn in the museum than in the school. Because it is concerned with learners not students, the museum can create a wide range of different learning opportunities for a broad number of people. This reach is of enormous importance to the European economy in the coming decades. As global finance and new technologies change the face of the working world, and people have to adjust rapidly to changes in the workplace, the informal learning environment becomes an important place to learn new skills - not only the skills involved in new technologies, but skills of communication, collaboration, and discussion. This socialisation has often been associated narrowly with the formal environment ${ }^{15}$, but is increasingly a feature of the informal learning environment, as the museum takes on the forum function in modern society. Whereas the formal system sees its success in terms of more students, the informal system succeeds in terms of more learners. To compete in the next century, we need more learners, not just more students - and we need to create a learning society.

Thus our institutions should take the initiative in developing new products and programmes with new media. As specialists in the informal environment we are well positioned to take a leading role in creating new approaches to informal learning, and new knowledge about how to support learning. We may not be alone in the field, nor should we be, but the new institution's future is guaranteed as long as we continue to take the initiative in creating rich learning opportunities - inside and outside, with and without our walls.

Paper prepared for the annual Spring meeting of the Danish Museums Association March 18, 1998

\section{NOTES}

1. This is of course not true for all science centre exhibits, and much of the work of the past three decades has been to create exhibits which allow real interaction, leave room for the visitor to ask 
and answer their own questions, and truly engage with the material. Sadly, many, if not most, science centre exhibits are still just devices that allow the visitor to set into motion principles or phenomena that someone finds interesting, and the so-called hands-on interaction merely turns the user into an extension of the exhibit, a soft hand to bring forth the phenomenon the designer or educator intended. This tendency for exhibits to become vehicles for the designer's, rather than the visitor's questioning was noted by science centre pioneer Frank Oppenheimer, founder of the San Francisco Exploratoriumß, who said «I don't want anyone to leave a science center thinking: 'Gee, isn't someone else clever.'”

2. Many studies bear out the importance of the emotional, or 'hearts-on' character of the museum visit, which stems in large part from its social nature, undertaken with family and friends.

3. It could be argued that the fact that the museum visit is most often an emotionally-charged, social occasion in the company of family and friends accounts in large measure for the observed frequency, and that even repeat visits based on this affective charge merely re-inforce the pattern of visits.

4. As an example, in 1997 , over $85 \%$ of the visitors to the Van Gogh Museum in Amsterdam were foreign tourists.

5. Yearbook of science center statistics 1997 ASTC; Washington; 1998.

6. See R. Russell, Attendance Projections: Real and Imagined, The Informal Science Review, No. 25, July/August 1997.

7. In the same issue of The Informal Science Review is the report that the Pacific Northwest Museum of Natural History, declared one of America's best new museums by the Smithsonian Institution, is closing in 1997 - after only opening in 1994! Issue No. 27 of the same Journal reports the closing of the Columbus Centre Hall of Exploration in Baltimore due to inadequate

8. Evidence of this phenomenon can be found in a privately commissioned feasibility study conducted for Erlebnis Wien by Ravest Associates in conjunction with Drew Ann Wake and the author.

9. See especially Cziksentmihalyi, M. Flow New York: Harpers; 1990 and Cziksentmihalyi, M., Talented Teens, New York: Harpers; 1990.

10. Preliminary data indicate that newMetropolis visitors spend substantially greater amounts of time engaging in the exhibits than at any other institution for which we have data. The average visit to newMetropolis is nearly five hours - a substantial investment in time for only $5,000 \mathrm{~m}^{2}$ of interactive exhibitions. Moreover, data also suggest that despite the emphasis on games and game playing, users do make the connection between the game activity and related social and technological issues.

11. In a recent project sponsored by a government ministry, Dutch citizens were asked to 'vote' on their choice of planning strategy for the future of the country in 2030. After substantial publicity, over 1,600 written ballots were sent in from throughout the country. To co-incide with this event, newMetropolis designed an interactive video debate on four of its 'Actua' computers. In this debate, users could listen to short video clips promoting different positions, and having heard at least four opposing positions, could vote. In the two months of the national poll, over 2700 'votes' were cast at newMetropolis - more than half of the entire poll! The complete data from this experiment will be published in late 1998 .

12. The 18 'Actua' computers at newMetropolis provide both open access to selected Internet information providers, and an extensive collection of sites linked specifically to each of newMetropolis's $150+$ exhibits. During an average week (@6 - 7,000 visitors), approximately 
JAMES M. BRADBURNE

$52 \quad 55,000$ pages of information are consulted.

13. Shortland, M. No business like show business Nature Vol. 328, 1987.

14. Since it opened in June 1997, newMetropolis has been conducting active research into the effectiveness of its exhibition strategies. This research is due to be published beginning in late 1998.

15. Notably in Bourdieu, P. and Darbel, A.

L'amour de l'art, Paris: Editions de minuit; 1969.

James M. Bradburne is AADipl MCSD, Director of newMetropolis, Science and Technology Center in Amsterdam.

Adr: newMetropolis, Science and Technology Center, Oosterdok 2, 1011 VX Amsterdam, The Netherlands Fax +31205313535

e-mail:bradburne@newmet.nl 